\begin{tabular}{l|l|l}
\hline & $\begin{array}{l}\text { Proceedings of the } \\
\text { Informing Science }+\end{array}$ & $\begin{array}{l}\text { An Official Publication } \\
\text { of the Informing Science Institute } \\
\text { InformingScience.org }\end{array}$ \\
\hline $\begin{array}{l}\text { Information Technology } \\
\text { Education Conference }\end{array}$ & InformingScience.org/Publications
\end{tabular}

\title{
EFFECTS OF MULTICULTURAL TEAMWORK ON INDIVIDUAL PROCRASTINATION [ABSTRACT]
}

Ruti Gafni*

Anat Goldstein

* Corresponding author
The Academic College of Tel Aviv Yaffo, Tel Aviv, Israel

The Academic College of Tel Aviv Yaffo, Tel Aviv, Israel rutigafn@mta.ac.il

anatgo@mta.ac.il

\section{ABSTRACT}

Aim/Purpose

Background

Methodology

Contribution

Findings
The purpose of this study is to discover usage differences in task performance by students of different cultures, by examining procrastination patterns from a national cultural perspective, exploring the effect of multicultural virtual teamwork on student's individual procrastination.

This study aims to examine higher-education entrepreneurial learning in the context of multicultural virtual teamwork, as actually performed during participation on a Global Entrepreneurship course.

In the examined course, there were 177 participants, from 3 different countries: United Kingdom, France and Israel. The students were grouped into 40 multicultural virtual (not face-to-face) teams, each one composed of at least participants of two countries. This research is based on analysis of objective data collected by Moodle, the LMS used in the In2It project, in its built-in log system, from the Global Entrepreneurship course website, which offer students diverse entities of information and tasks. The primary methodology of this study is analytics of the extracted data.

This study aims to discover the effects of multicultural teamwork on individual procrastination, while comparing the differences between cultures, as there are only a few studies exploring this relation. The uniqueness of this study is also by using and analyzing actual data of student procrastination from logs, while other studies of procrastination in multicultural student teams have measured perceived procrastination, collected using surveys.

Results show statistical differences between countries in procrastination of individual assignments before team working: students from UK were the most procrastinators and Israeli students were the least procrastinators, but almost all students procrastinated. However, the outcome of the teamwork was submitted almost without procrastination. Moreover, procrastination in

The full version of this paper is published in the Interdisciplinary Journal of e-Skills and Lifelong Learning (IJELL) at https://doi.org/10.28945/4617.

(CC BY-NC 4.0) This article is licensed to you under a Creative Commons Attribution-NonCommercial 4.0 International License. When you copy and redistribute this paper in full or in part, you need to provide proper attribution to it to ensure that others can later locate this work (and to ensure that others do not accuse you of plagiarism). You may (and we encourage you to) adapt, remix, transform, and build upon the material for any non-commercial purposes. This license does not permit you to use this material for commercial purposes. 
Recommendations for Practitioners

Recommendation for Researchers Impact on Society

Future Research

Keywords individual assignments performed after finishing the multicultural teamwork, dramatically decreased to $10 \%$ of the students' prior individual procrastination.

The results from this study, namely, the decline of the procrastination after the multicultural virtual teamwork, can be used by global firms with employees all over the world, working in virtual multicultural teams. Such firms do not need to avoid multicultural teams, working virtually, as they can benefit from this kind of collaboration.

These results can be also beneficial for academic researchers from different cultures and countries, working together in virtual multicultural teams.

Understanding the positive effect of virtual multicultural teamwork, in mitigating the negative tendency of students from diverse cultures to procrastinate, as concluded in this study, can provide a useful tool for higher education or businesses to mitigate procrastination in teamwork processes. It can also be used as an experiential learning tool for improving task performance and teamwork process.

The relation between procrastination and motivation should be further examined in relation to multicultural virtual teams. Further research is needed to explore the effect of multicultural virtual teamwork during the teamwork process, and the reasoning for this effect.

procrastination, virtual teams, multicultural teams, individual procrastination

\section{BIOGRAPHIES}

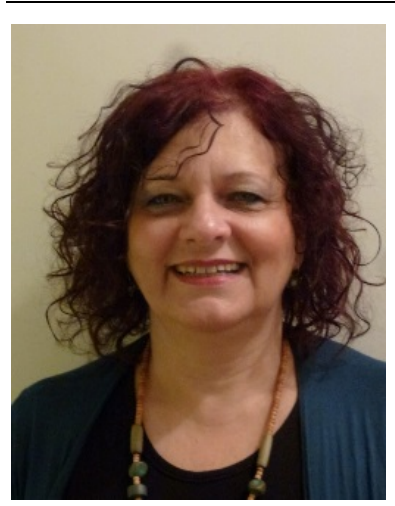

Ruti Gafni is an Associate Professor and the Head of the Information Systems B.Sc. program at The Academic College of Tel Aviv Yaffo. She holds a PhD from Bar-Ilan University, Israel (in the Business Administration School), focusing on Information Systems, an M.Sc. from Tel Aviv University and a BA (Cum Laude) in Economics and Computer Science from Bar-Ilan University. She has more than 40 years of practical experience as Project Manager and Analyst of information systems.

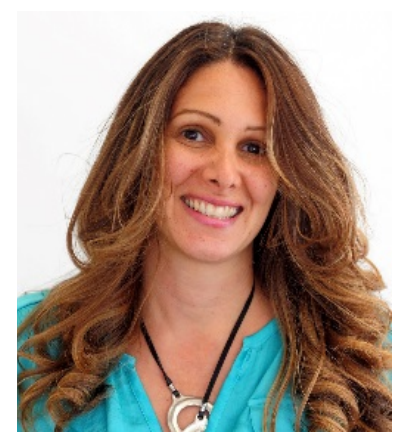

Anat Goldstein is a lecturer at the Information Systems B.Sc. program, and the Head of the Entrepreneurship track in the Management and Economics B.A program, at The Academic College of Tel-Aviv-Yaffo. She holds an MA in Education management and an L.L.B (LAW) from Tel Aviv University. She is currently working on her $\mathrm{PhD}$ focusing on virtual technological platforms for entrepreneurial learning. Anat has more than 15 years of practical experience as senior marketing and business development director in the High-tech sector, and in Corporates. She has more than 5 years' experience in developing and managing face-to-face and virtual Hackathons and Accelerators. 